\title{
UPGRADES OF THE EPITHERMAL NEUTRON BEAM AT THE BROOKHAVEN MEDICAL RESEARCH REACTOR
}

\author{
Hungyuan B. Liu*, Robert M. Brugger", and David C. Rorer ${ }^{\dagger}$ \\ *Medical Department, Brookhaven National Laboratory, Upton, New York 11973, USAOCT 101885
†Reactor Division, Brookhaven National Laboratory, Upton, New York 11973, USA

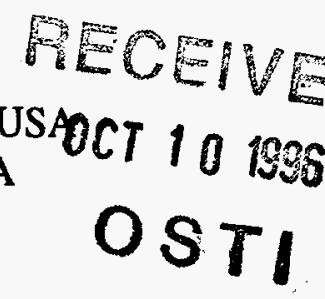 \\ 1. ABSTRACT
}

The first epithermal neutron beam at the Brookhaven Medical Research Reactor (BMRR) was installed in 1988 and produced a neutron beam that was satisfactory for the development of NCT with epithermal neutrons. This beam was used routinely until 1992 when the beam was upgraded by rearranging fuel elements in the reactor core to achieve a $50 \%$ increase in usable flux. Next, after computer modeling studies, it was proposed that the $\mathrm{Al}$ and $\mathrm{Al}_{2} \mathrm{O}_{3}$ moderator material in the shutter that produced the epithermal neutrons could be rearranged to enhance the beam further. However, this modification was not started because a better option appeared, namely to use fission plates to move the source of fission neutrons closer to the moderator and the patient irradiation position to achieve more efficient moderation and production of epithermal neutrons. A fission plate converter (FPC) source has been designed recently and, to test the concept, implementation of this upgrade has started. The predicted beam parameters will be 12 $x 10^{9} \mathrm{n}_{\mathrm{epi}} / \mathrm{cm}^{2} \mathrm{sec}$ accompanying with doses from fast neutrons and gamma rays per epithermal neutron of $2.8 \times 10^{-11}$ and $<1 \times 10^{-11} \mathrm{cGycm}^{2} / \mathrm{n}$, respectively, and a current-to-flux ratio of epithermal neutrons of 0.78 . This conversion could be completed by late 1996 .

\section{INTRODUCTION}

The Brookhaven Medical Research Reactor (BMRR) is an adjunct facility to the Medical Research Center of the Brookhaven National Laboratory (BNL) $)^{\mathbf{l}}$. The reactor operates at powers up to $3 \mathrm{MW}$. It has facilities for extracting beams that facilitate modifications and future beam developments. The BMRR was first operated in 1959 to deliver an intense beam of thermal neutrons for NCT. Between 1959 and 1961, 17 patients were treated at BMRR ${ }^{2}$. Analysis of the results of these early clinical trials showed little significant therapeutic effect. The experimenters concluded that the ${ }^{10} \mathrm{~B}$ compound did not concentrate and persist in the tumor cells, and that thermal neutrons did not penetrate to adequate depths. Failure to demonstrate substantial extensions of life resulted in suspension in 1961 in the USA of NCT clinical trials at BMRR.

Development of NCT restarted at BNL in the 1980s. The renewed development of NCT has focused on epithermal neutron beams and improved ${ }^{10} \mathrm{~B}$ compounds that will enhance the dose at the tumor. At BMRR there are two neutron beam irradiation ports, each within a shielded room, on opposite faces of the BMRR. Each room is separated from the reactor core by a shutter. In 1988, $\mathrm{Al}$ and $\mathrm{Al}_{2} \mathrm{O}_{3}$ were selected as a primary moderator and these were placed in one of the existing beam shutters to produce an epithermal neutron beam ${ }^{3,4}$. Table 1 lists beam parameters as these existed from 1988 till 1992. At present, the other beam is a thermal neutron beam $^{5}$. The beam shutters with their moderator assemblies can be raised and lowered 
hydraulically inside a vertical cavity to control the irradiation. Figure 1 depicts a mid-plane horizontal section (as it now exists) of the BMRR epithermal irradiation facility extending from the reactor core out to the irradiation port.

In 1959, the reactor started up with 17 new fuel elements and with time, some fuel was burned up. To replace reactivity, the partially burned elements were not removed, but new elements were added until, in May 1992, there were 30 partially spent fuel elements in the reactor core and a new one was needed. In June 1992, one new fuel element was added to the reactor core in place of a graphite spacer block. The reactor core was reconfigured in October 1992 to move elements closer to the epithermal port. There are now 31 fuel elements in the reactor core with four new fuel elements facing the epithermal irradiation port. After this core reconfiguration, the epithermal neutron beam gained $50 \%$ in intensity while the fast-neutron and gamma dose rates increased only $36 \%$ and $34 \%$, respectively. The current beam parameters in air at $\mathrm{Y}$ are listed in Table 1.

After a computer modelling study, a change of the $\mathrm{Al}$ and $\mathrm{Al}_{2} \mathrm{O}_{3}$ moderator section in the beam shutter was proposed ${ }^{6}$. The rearrangement is shown in Figure 2. With this proposed change, the beam was expected to increase $30 \%$ in intensity while the fast-neutron dose per epithermal neutron could be reduced by $30 \%$ at $Y^{\prime}$ (see Table 1). This modification was not started because a better option appeared ${ }^{7}$.

\section{FISSION PLATE CONVERTER BEAM}

In the new modification, a Fission Plate Converter (FPC) would be used to move the source of fission neutrons closer to the moderator and the patient irradiation position to achieve more efficient moderation and production of epithermal neutrons. Recently, such a FPC has been designed for the BMRR and implementation of this upgrade has been started to test this concept.

Figure 3 depicts the proposed design of the FPC at the BMRR epithermal irradiation facility. Eight surplused U fission plates from the Janus reactor at the Argonne National Laboratory will be incorporated into a new beam shutter. Each plate contains about $1 \mathrm{~kg}$ of ${ }^{235} \mathrm{U}$ as $20 \%$ enriched metal clad with $0.0254 \mathrm{~cm}$-thick steel. Pairs of these plates will be sandwiched between two Al plates. Then, each sandwich will be back filled with $\mathrm{He}$ and the edges welded to form a second barrier. Light-water coolant channels will be machined directly in the $\mathrm{Al}$ enclosure to provide necessary cooling to these FPC units. After the FPC assembly, a moderator section with total $48 \mathrm{~cm}$-thick $\mathrm{Al}$ and $28 \mathrm{~cm}$-thick $\mathrm{Al}_{2} \mathrm{O}_{3}$ materials $(1.27 \mathrm{~cm}$-thick $\mathrm{Al}_{2} \mathrm{O}_{3}$ tiles with $0.318 \mathrm{~cm}$-thick $\mathrm{Al}$ sheets) will be placed in the shutter.

At the irradiation port, additional $\mathrm{Bi}$ and $\mathrm{Pb}$ shielding and high-density concrete will be added to provide a minimum of $10 \mathrm{~cm}$ of $\mathrm{Bi}$ and/or $\mathrm{Pb}$ in the beam line to shield from gamma radiation. The irradiation port will be a square opening of $25.4 \mathrm{~cm} \times 25.4 \mathrm{~cm}$ with a $20 \mathrm{~cm}$ long beam path to direct the beam forward. The irradiation point (" $Z$ " in Figure 3) is $195 \mathrm{~cm}$ away from the center of the reactor core. The beam parameters in air at $\mathrm{Z}$ are listed in Table 1 for comparisons. The design was made by MCNP computations with benchmarks to measurements of the present thermal neutron flux near the planned location for the FPC. 


\section{DISCLAIMER}

This report was prepared as an account of work sponsored by an agency of the United States Government. Neither the United States Government nor any agency thereof, nor any of their employees, makes any warranty, express or implied, or assumes any legal liability or responsibility for the accuracy, completeness, or usefulness of any information, apparatus, product, or process disclosed, or represents that its use would not infringe privately owned rights. Reference herein to any specific commercial product, process, or service by trade name, trademark, manufacturer, or otherwise does not necessarily constitute or imply its endorsement, recommendation, or favoring by the United States Government or any agency thereof. The views and opinions of authors expressed herein do not necessarily state or reflect those of the United States Government or any agency thereof. 


\section{DISCLAIMER}

Portions of this document may be illegible in electronic image products. Images are produced from the best available original document. 


\section{RESULTS and CONCLUSIONS}

The proposed epithermal neutron beam with a FPC source could increase the epithermal neutron flux of the present BMRR beam by as much as $670 \%$ and reduce the fast-neutron dose per epithermal neutron by $33 \%$. The calculated fission heat generated in the eight fission plates with the reactor at $3 \mathrm{MW}$ is about $72 \mathrm{~kW}$ and the total emission rate of fission neutrons from the plates is about $5.5 \times 10^{15} \mathrm{n} / \mathrm{sec}$. At $Z$, the neutron beam would consist of $>90 \%$ epithermal neutrons, $<5 \%$ thermal neutrons, and $<5 \%$ fast neutrons. The beam would be directed forward with a neutron current-to-flux ratio of 0.78 . Outside the irradiation port, $20 \mathrm{~cm}$ perpendicularly off the beam centerline at the surface of the Li-poly shield, the beam intensity would be reduced to less than $3 \%$ compared to the intensity at $\mathrm{Z}$.

One additional calculation has been made. This is for the 1996 modification but with the FPC assembly removed. At $3 \mathrm{MW}$ reactor power, this design delivers an epithermal neutron flux of $2.0 \times 10^{9} \mathrm{n} / \mathrm{cm}^{2} \mathrm{sec}$ which would still be quite satisfactory for NCT.

The original design at BMRR produced a satisfactory beam of epithermal neutrons for NCT development. Modifications of the moderator and reactor core have allowed the beam to be enhanced. The proposed modification using a FPC source indicates that a significant additional improvement can be made. Testing of this concept is moving ahead at BNL.

(Research is supported by the US Department of Energy)

\section{REFERENCES}

1. J. B. Godel, Description of facilities and mechanical components; Medical Research Reactor (MRR), Brookhaven National Laboratory report, BNL 600 (T-173), Feb. 1960.

2. D. N. Slatkin, "A history of boron neutron capture therapy of brain tumours; postulation of a brain radiation dose tolerance limit," Brain 114:1609-1629, 1991.

3. F. Wheeler, et al., "Epithermal neutron beam design for neutron capture therapy at the PBF and BMRR reactor facilities," Nucl. Tech. 92:106-117, 1990.

4. R. G. Fairchild, J. Kalef-Ezra, S. K. Saraf, S. Fiarman, E. Ramsey, L. Wielopolski, B. H. Laster, F. J. Wheeler, "Installation and testing of an optimized epithermal neutron beam at the Brookhaven Medical Research Reactor (BMRR)," Neutron Beam Design, Development, and Performance for Neutron Capture Therapy, O. K. Harling et al., eds, pp. 185-199, 1990.

5. H. B. Liu, D. D. Joel, D. N. Slatkin, J. A. Coderre, "Improved apparatus for neutron capture therapy of rat brain tumors," Int. J. Radiat. Oncol. Biol. Phys. 28:1167-1173, 1994.

6. H. B. Liu, R. M. Brugger, D. D. Greenberg, D. C. Rorer, J. P. Hu, H. M. Hauptman, "Enhancement of the epithermal neutron beam used for BNCT at the BMRR." Int. J. Radiat. Oncol. Biol. Phys. 28:1149-1156, 1994. 
7. H. Rief, R. Van Heusden, G. Perlini, "Generating epithermal neutron beams for BNCT at TRIGA reactors," Advances in Neutron Capture Therapy, A.H. Soloway et al., eds, pp. 85-88, Plenum Press, New York, 1993.

\section{FIGURE CAPTIONS}

Figure 1. A horizontal section at the mid plane of the BMRR as it is after the rearrangement of the core in 1992. The 31 fuel elements are shown as black squares in the tank. Patients are placed at $\mathrm{Y}$.

Figure 2. The BMRR with the proposed rearrangement of the $\mathrm{Al}$ and $\mathrm{Al}_{2} \mathrm{O}_{3}$ moderator materials in the shutter. This modification has not been made.

Figure 3. The proposed modification of the BMRR epithermal beam with the fission plate converter on the left-hand side of the shutter and the $\mathrm{Al}$ and $\mathrm{Al}_{2} \mathrm{O}_{3}$ moderator materials on the right-hand side of the shutter. Patients would be placed at $\mathrm{Z}$. 
Table 1. BMRR epithermal neutron beam parameters in air at the irradiation port for 3 MW operating power.

\begin{tabular}{|l|r|r|r|r|}
\hline & $\begin{array}{l}\text { Epithermal } \\
\text { flux } \\
\left(10^{9} \mathrm{n} / \mathrm{cm}^{2} \mathrm{sec}\right)\end{array}$ & $\begin{array}{l}\text { Fast-neutron dose } \\
\text { per epi-neutron } \\
\left(10^{-11} \mathrm{cGycm}^{2} / \mathrm{n}\right)\end{array}$ & $\begin{array}{l}\text { Gamma dose per } \\
\text { epi-neutron } \\
\left(10^{-11} \mathrm{cGycm}^{2} / \mathrm{n}\right)\end{array}$ & $\begin{array}{l}\text { Neutron } \\
\text { current-to- } \\
\text { flux ratio }\end{array}$ \\
\hline $\begin{array}{l}\text { First epithermal } \\
\text { beam } \\
(1988-1992)\end{array}$ & 1.2 & 4.8 & 1.4 & 0.67 \\
\hline $\begin{array}{l}\text { Reconfigured } \\
\text { core } \\
\text { (1992-present) }\end{array}$ & 1.8 & 4.3 & 1.3 & 0.67 \\
\hline $\begin{array}{l}\text { Modified } \\
\text { moderator } \\
\text { (not built) }\end{array}$ & 2.4 & 3.0 & 1.3 & 0.72 \\
\hline $\begin{array}{l}\text { Fission plate } \\
\text { converter } \\
\text { (1996-) }\end{array}$ & 12 & 2.8 & $<1.0$ & 0.78 \\
\hline $\begin{array}{l}\text { 1996 } \\
\text { modification } \\
\text { w/o FPC }\end{array}$ & 2.0 & & & \\
\hline
\end{tabular}




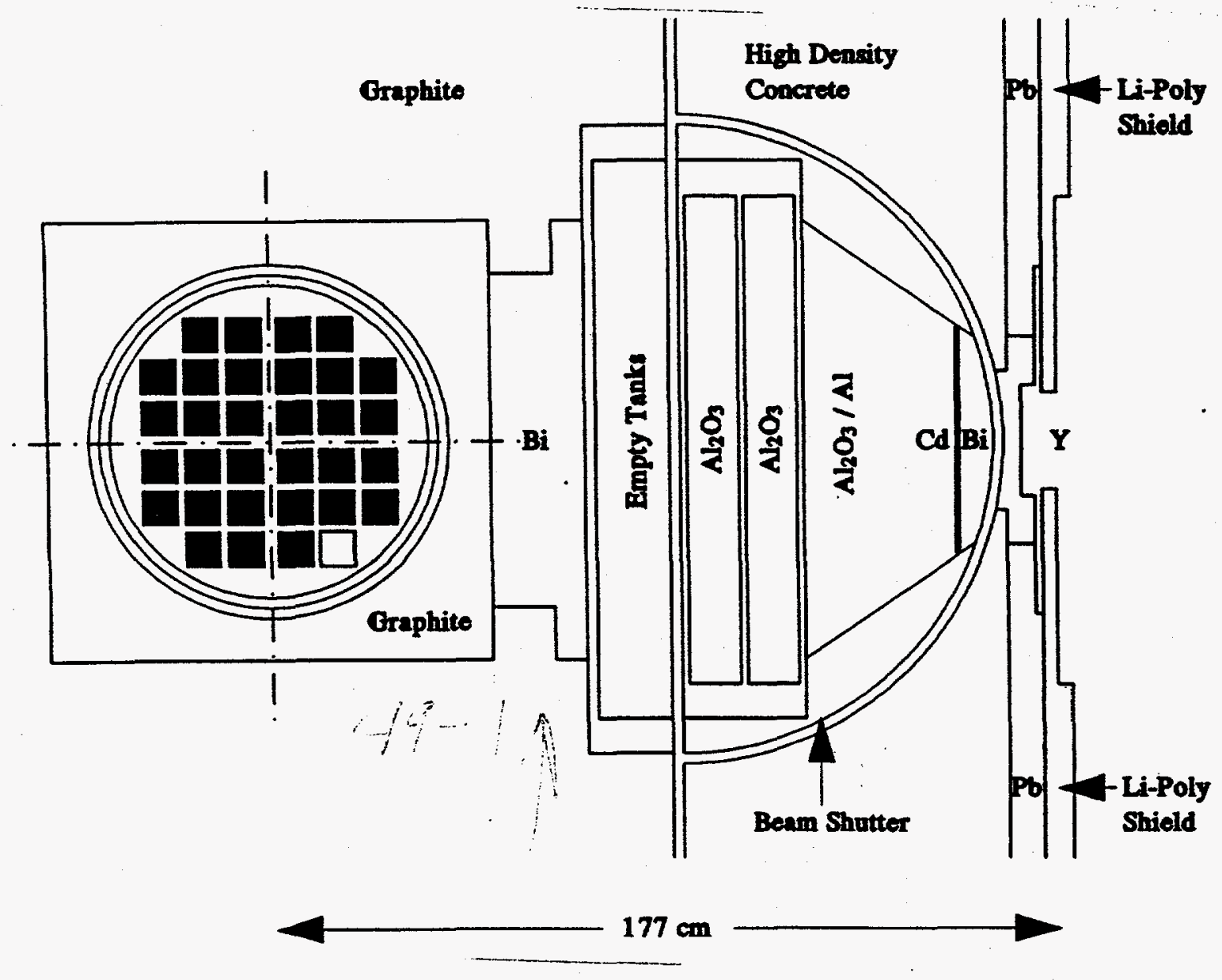

Liu 49

Figure 1

w: 37 H: 29 


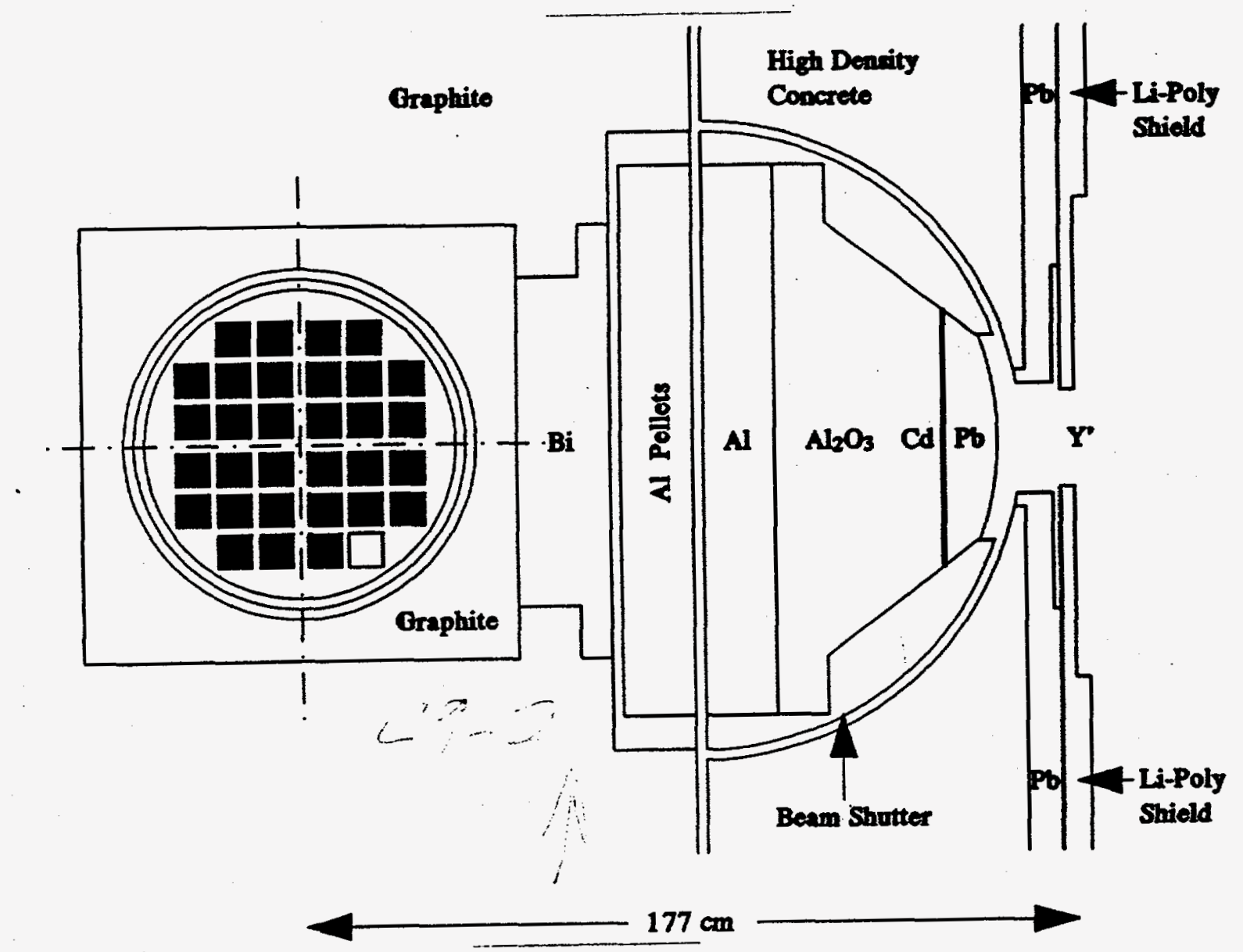

Liu 49

Figure 2

w: $37 \mathrm{H}: 29$ 


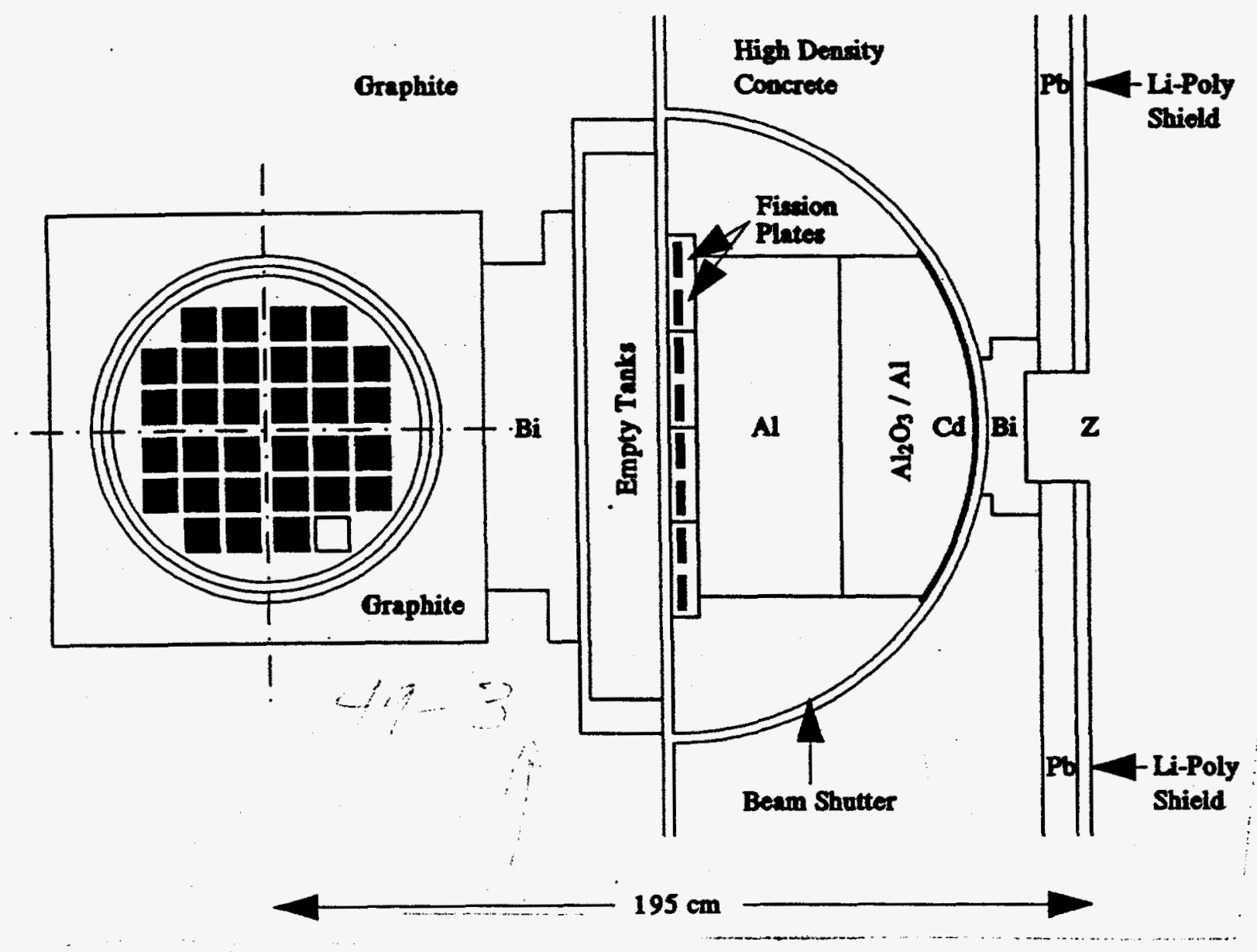

\section{Liu 49}

Figure 3

w: 33 н: $2 \mathbf{i}^{2}$ 